\title{
Regional aging and longevity characteristics in China
}

\author{
Li Wang ${ }^{\mathrm{a}, \mathrm{b}}$, Yonghua $\mathrm{Li}^{\mathrm{a}, *}$, Hairong $\mathrm{Li}^{\mathrm{a}}$, Jennifer Holdaway ${ }^{\mathrm{c}}$, Zhe Hao ${ }^{\mathrm{a}, \mathrm{d}}$, Wuyi Wang ${ }^{\mathrm{a}}$, \\ Thomas Krafft ${ }^{\mathrm{a}, \mathrm{b}}$ \\ ${ }^{a}$ Key Laboratory of Land Surface Pattern and Simulation, Institute of Geographic Sciences and Natural Resources Research, Chinese Academy of Sciences, \\ Beijing,100101, China \\ ${ }^{\mathrm{b}}$ Faculty of Health, Medicine and Life Sciences, Maastricht University, 6229ER, The Netherlands \\ ' School of Interdisciplinary Area Studies, University of Oxford, OX2 6LH, Oxford, United Kingdom \\ ${ }^{\mathrm{d}}$ Key Laboratory of Engineering Oceanography, Second Institute of Oceanography, SOA, Hangzhou 310012, China
}

\section{A R T I C L E I N F O}

\section{Article history:}

Received 23 February 2016

Received in revised form 2 August 2016

Accepted 3 August 2016

Available online 12 August 2016

\section{Keywords:}

Aging

Centenarians

Behavior

Economic

Geographical distribution

\section{A B S T R A C T}

The factors that influence the length of human life are complex and longevity remains a controversial topic, particularly in China. This paper demonstrates the spatial patterns and changes of the elderly group (65 years old and over), the oldest old ( 80 years old and over) and the centenarians in China in the last decade, analyzes the influence of economic development on aging, and in the end, using a case study, explores the characteristics of the centenarians' behavior. The results indicate that high elderly and the oldest old proportions are more common in regions with higher socio-economic development and that have a favorable climate. Centenarian distribution pattern is less influenced by economic but only for few regions. Lifestyle factors, such as sufficient sleep, positive mental state and a light diet are also largely found among the centenarian group.

(c) 2016 Elsevier Ireland Ltd. All rights reserved.

\section{Introduction}

Life expectancy in China has increased significantly over the last three decades, with the national average rising from 69 in 1980 to 74.8 in 2010. Since 2000 China has been an aging society, with $10.33 \%$ of the population aged 60 and over. According to the China's sixth national population census in 2010 (China statistical yearbook, 2000, 2010), there were 178 million people aged 60 and over, accounting for $13.26 \%$ of the whole population, and 119 million people aged 65 and over, accounting for $8.87 \%$ of the whole population. The proportions of the two groups have increased by $2.93 \%$ and $1.91 \%$ since 2000 . By 2050 , China's elderly population $(65+)$ will likely increase to 330 million, around a quarter of its total population. In addition to overall population aging, the annual growth rates of the oldest old ( 80 years and over) and centenarians have also increased by $6 \%$ and $10 \%$ since 2000 (WHO, 2011). These demographic changes reflect the dramatic social and economic development that has taken place in China since the reform and open-up, along with enhanced medical services and improved nutrition. This period has been free of famine, war and political

\footnotetext{
* Corresponding author at: Institute of Geographic Sciences and Natural Resources Research, Chinese Academy of Sciences, 11 A Datun Road, Beijing 100101, China.

E-mail address: yhli@igsnrr.ac.cn (Y. Li).
}

upheavals that lowered life expectancy in earlier periods of China's history, and poverty and the diseases associated with it have declined rapidly. Although there was a slight uptick since 1995 , many fatal and debilitating infectious diseases were eliminated or effectively controlled, including plague, polio and smallpox, which were eradicated as early as the 1960s. The overall infectious disease mortality rate dropped from 66 cases per million in 1975 to 5 cases per million in 1995 (Zhang \& Wilson, 2012), and by 2004, 59\% of deaths were from non-communicable diseases (Banister, Bloom, \& Rosenberg, 2010). Along with the decline in maternal and child health problems, this marked a rapid epidemiological transition (Yang et al., 2013). In the meanwhile, rapid economic growth also provided both material and spiritual satisfaction, which largely contributed to the life expectancy.

Longevity is the ultimate symbol of health and happiness, but the factors that contribute to a healthy old age are complex. Researchers have shown that longevity is not only affected by genetic factors (WHO, 2011), but also by physiological, psychological, socio-economic, and natural factors, among others (Lv et al., 2011a,b; WHO, 2011; Robine et al., 2012). Facing the rapid aging in China, which will bring new challenges for society, an understanding on the regional variations of aging and the determinants that contribute to longevity is urgently needed in order to design policies to support healthy aging in different contexts. In this paper we firstly display the spatial distribution and changes of the aging 
population and longevity groups across China at prefecture-level in 2000 and 2010. Then Pearson Correlation and Geographically Weighted Regression (GWR) are used to explore the economics' influence on the aging. In the end, a case focusing on centenarians in Hainan province is used to explain the structure and behavior features of centenarians. The major objectives of this paper are: 1) to demonstrate the spatial distribution of aging and its change in China; 3 ) to explore the possible influence of economic development on aging; 2) and to identify the behavior characteristics of centenarians under the hypothesis of individual factors associating with longevity in China. The research findings provide entry-points for social and policy on developing healthy aging strategies.

\section{Methods}

In this paper, the elderly are defined as those aged 65 and over $(65+)$, the oldest old is composed of people aged 80 and over (80+), and centenarians are those aged 100 and over (100+). Aging data were obtained from the demographic database of the fifth and sixth national population censuses of China, which were carried out in 2000 and 2010 respectively (China statistical yearbook, $2000,2010)$. In order to explore the possible influence of economic status to aging, we conducted Pearson Correlation using SPSS 19.0. Geographically Weighted Regression was conducted through centenarian proportion against per Capita GDP in 2010 to explore the spatial correlation between economic growth and centenarian proportion at local level (Wang et al., 2014). Geographic Information Systems (ArcGIS 10.0) was used to display the distribution maps of the elderly, the oldest old and the centenarians at Prefecture-level. Origin 8.0 was used to draw the figures for the case study.

In order to explore the characteristic of the longevity, we choose Hainan province, which has the highest proportion of centenarians in China, as a case study area. Hainan province is one of the provinces with highest life expectancy of 76.3 in China in 2010, and is recognized by the International Expert Committee on Population Aging and Longevity as a World Longevity Island on August 27, 2014 for its highest percentage of centenarians $(18.75 / 100,000)$ in China (China NBS, 2011). There were totally 1600 registered centenarians in the HUKOU system in total 18 administrative divisions (county or city level) in Hainan province in 2012. From February 2012 to September 2012, we collected 10 questionnaires from each administrative division in the beginning, and then based on the proportion of the centenarians to the total population in each administrative division, another 43 questionnaires were collected. In the end, 223 questionnaires were collected covering all the 18 administrative divisions in Hainan province. We filled the questionnaires by face to face interview, or with the help of their caregivers. All the questionnaires were geographic evenly collected from each administrative division. The questionnaire was selfdesigned based on the SF-36 health survey: manual and interpretation guide (Ware, Snow, Kosinski, \& Gandek, 1993). The methods were carried out in accordance the approved guidelines and regulations of the Institute of Geographical Sciences and Natural Resources Research, Chinese Academy of Science, and the study was approved by the Institute of Geographical Sciences and Natural Resources Research, Chinese Academy of Science, and Hainan Government. Informed consents were obtained from all the participants for the study. The information from the questionnaire can be summarized as Table 1 .

\section{Results}

\subsection{Demographic characteristics and their geographical distribution}

In 2010, an estimated 524 million people were aged 65+, accounting for $8 \%$ of the world's population, and by 2050 , this proportion was expected to double to $16 \%$ (WHO, 2011). The depth and speed of aging varies considerably among countries and regions. Most developed countries already have aged populations, while aging is just taking off in developing countries, and it is predicted that the aging will proceed much more rapidly in developing countries now than in the developed countries, for example 26 years for China, compared with 115 years for France and 85 years for Sweden (Kinsella \& Phillips, 2005). The consequence is that the trend in the number of older persons in the world is dominated by the accelerated growth of the older population in the less developed regions, and even though two thirds of the world's older persons are located in developing countries presently, this ratio will continue growing in 2050 . In particular, China will see an increase of 15.7 percentage points in the proportion of the elderly people, reaching $28.1 \%$ in 2050 (United Nations, 2013). Unlike the aging distribution, around 69\% of the centenarians live in developed countries, and it is predicted that the vast majority of the centenarians will still be located in developed countries by 2050 (United Nations, 2013).

Fig. 1a-e show the distributions of people aged 65+ (2000 and 2010), $80+(2000$ and 2010), and $100+$ at the prefecture city level using data from the fifth and sixth national census. The geographical distribution of the elderly, oldest old and centenarians groups in China is characterized by regional clustering in both 2000 and 2010. The proportions of the elderly and the oldest old among the total population increased dramatically from 2000 to 2010 . The proportion of the elderly people increased from $6.96 \%$ to $8.87 \%$ in total. Although with obvious increase, the spatial distribution patterns of the elderly proportions in 2000 and 2010 are similar, with the higher ratios located in the Yangtze River Delta, the Sichuan-Jiangsu region, and the Bohai region. Natong

Table 1

Parameters included in the questionnaire.

\begin{tabular}{|c|c|}
\hline Questions & Details \\
\hline Name & - \\
\hline Age & - \\
\hline Gender & Male/female \\
\hline Address & County/town/street \\
\hline Marital status & Single/married \\
\hline Living condition & Along/with partner/with heirs \\
\hline Medical consultation & Less than 1 time $/ 1$ time $/ 2$ times/more \\
\hline Sleeping hour & Less than $8 \mathrm{~h} / 9 \mathrm{~h} / 10 \mathrm{~h} / 11 \mathrm{~h} /$ more \\
\hline Self-assessment on sleeping quality & Very good/good/no clue/not good/bad \\
\hline The most common attitude during daily life & Let it be/happy/nervous(fear)/feel alone \\
\hline Staple food & Rice/noodle/crop/grains/mixed/other \\
\hline Food habit & Light/slightly salty/slightly spicy/sweet \\
\hline
\end{tabular}



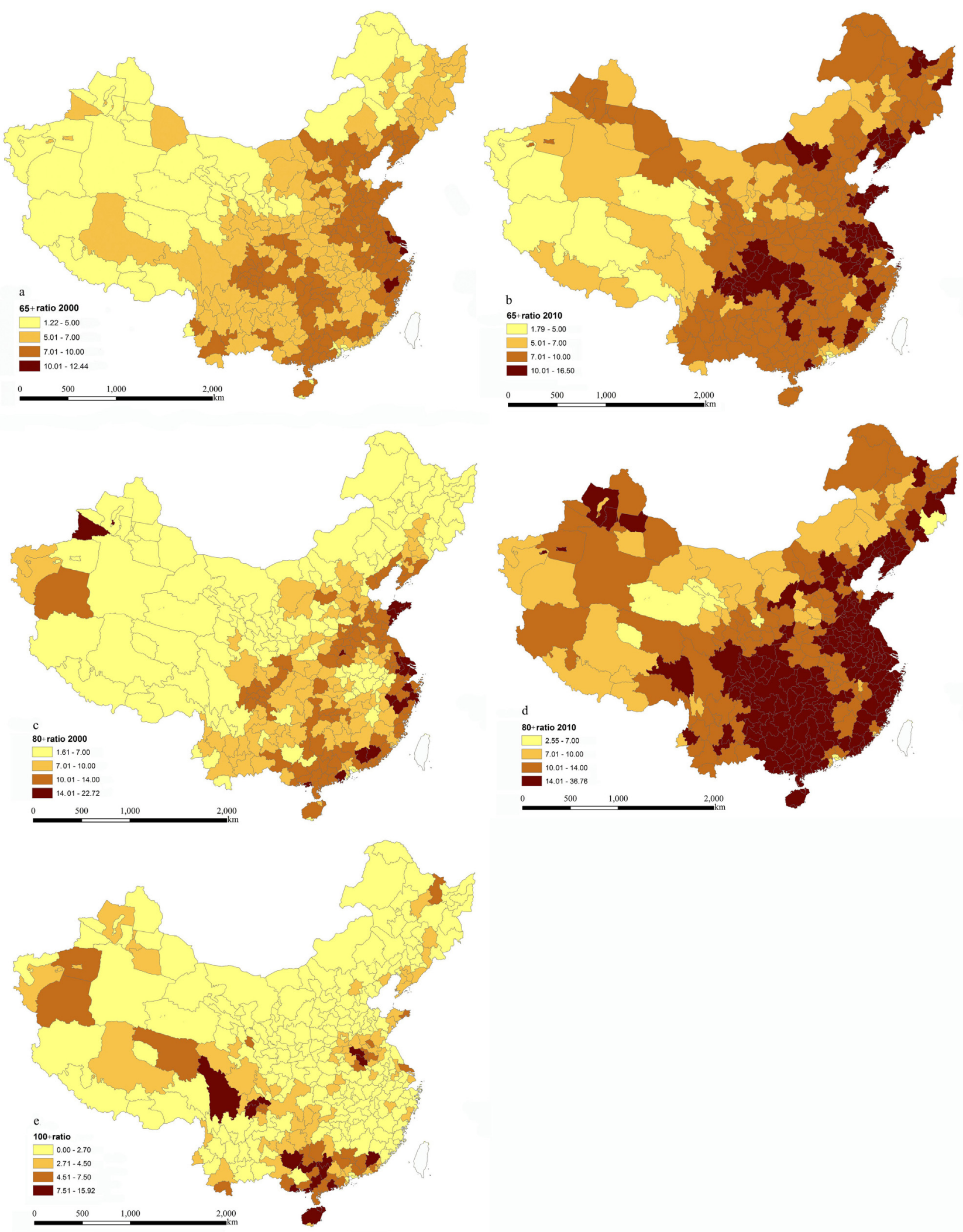

Fig. 1. Geographical distributions of the proportion of people aged 65+(a-2000, b-2010; per 100), 80+(c-2000, d-2010; per 1000), and 100+ (e-2010; per 100,000) groups at the prefectural city level. The maps were generated by L.W. and Y.-H. L., using ArcGIS 10.0 (http://www.esri.com/software/arcgis/arcgis-for-desktop) with the license from the Institute of Geographic Sciences and Natural Resources Research, Chinese Academy of Sciences. The projected coordinate system was Krasovsky_1940_Albers. The boundary map (1:30 000 000) was obtained from the National Administration of Surveying, Mapping and Geoinformation (http://219.238.166.215/mcp/index.asp). 
(16.5) and Taizhou (14.23) regions of Jiangsu province had the highest proportion of people aged 65+ in 2010, followed by Ziyang (13.6), Meishan (13.3) and Zigong (12.7) in Sichuan province.

As can be seen from Fig. 1c and d, the oldest old proportions expanded dramatically from 2000 to 2010 . The spatial distribution pattern is similar with the elderly group. Regions with higher proportion of the oldest old were mainly located in the East coastal areas in 2000, more specifically in the three major economic centers (Beijing-Tianjin, the Yangtze River Delta, and Pearl River Delta). These are regions with abundant natural resources and well-developed economies. Consistent with previous studies, a higher likelihood of healthy survival in those regions might be the result of avoiding hunger, a nutritionally-balanced diet, adequate access to medical services, better education, etc. (Brown, Qiu, \& Gu, 2012; Costa, 2005). In 2010, regions with higher oldest old proportion expanded largely in the East coastal area. In the meanwhile, provinces including Sichuan, Guangxi, Guizhou, Hunan, Hubei and the Northeast also emerged much higher proportion of oldest old compared with 2000 . This new emerging is more likely a function of the general economic improvements which might be slower in these regions compared to the coastal areas of China over the last few decades but still all parts of China have seen improvement and with those improvements have come longer life expectancy at the population level. Regions with the highest oldest old proportions are Ziyang (3.67) in Sichuan province, Nantong (3.65) in Jiangsu province, Meishan (3.63) in Sichuan province, Shanghai (3.57), and Quzhou (3.46) in Zhejiang province in 2010. Overall, regions with the highest proportions of the elderly and the oldest old are mostly located in the southeast part of the "Hu line" (also referred as the Heihe-Tengchong Line) (Hu, 1935), the climate boundary which largely shaped the economic development in China.

The ratio of centenarians in the population has been increasing. In 2010 , the average centenarian ratio was 2.7 per 100,000 , up from 1.44 per 100,000 in 2000 . However, the centenarian ratio was still considerably low compared with 4.4 per 100,000 averagely in the world. Unlike the elderly and the oldest old groups, the regions with the highest proportion of centenarians mainly clustered in Guangxi, Hainan, partly Henan and Sichuan province, where the economic is considerably less developed. But all of those regions have hilly geography, alluvial plains, and low levels of endemic diseases (Banister et al., 2010). The prefecture-level cities with top five high centenarian proportions are the provincial-counties in Hainan province (15.90), Meishan (13.65) in Sichuan province, Hechi (12.49), Wuzhou (12.23) and Beihai (10.32) in Guangxi province.

\subsection{The influence of economic to aging in China}

In order to explore the possible influence of economic to aging, we firstly conducted Pearson Correlation using the ratios of the proportions in 2010-2000 for three age groups, and the ratio of the per Capita GDP in 2010 and 2000 (Table 2).

The economic has significant positive association with the elderly proportion, and has significant positive association with the oldest old proportion at the 0.05 level. No significant correlations between economic and centenarian ratio is found.
In order to explore if there is any correlation at local scale between economic and centenarian ratio, we use GWR to regress the oldest old proportion against per Capita GDP using the data in 2010. Fig. 2 shows the local R-square of the spatial correlation.

Per Capita GDP has significant positive association with centenarian proportion in Beijing-Tianjin-Hebei region, Henan province, Xinjiang Autonomous Region and partly Hunan province. Combining with Fig. 1e, regions with higher centenarian proportions are not exclusively the ones with strong correlations between economic and centenarian proportion, indicating that economic could influence the lifespan, but it is not the leading cause for the extreme high centenarian proportions in Hainan, Guangxi and Sichuan province. The strong correlation in Henan province could partly explain the increasing centenarian proportion in this region. Apart from genetic and socio-economic factors, the clustered distributions of the extreme high proportion of centenarian might be attributed to the mixed and interacted factors among climate, natural environment and culture that could influence the individual behavior (Lv et al., 2011a,b; Liu et al., 2013; Martin, Poon, Kim, \& Johnson, 1996; Robine et al., 2012).

\subsection{Longevity characteristics in China: a case study in a typical Chinese longevity area}

In order to explore the life behavior characteristic of centenarians in China under the assumption that individual behavior could influence life span, interview was conducted with 223 centenarians in Hainan province because it had the highest proportion of centenarians and highest life expectancy in China. Among the centenarians, the oldest one was 112 years old, and the average age was 103 years old. Fig. 3 shows the results of the questionnaires and interviews. $80 \%$ of the sample reported being between 100-105 years old, with the number decreasing rapidly after 105 years old (Fig. 3a). Centenarian females were four times as numerous as males (Fig. $3 \mathrm{~b}$ ).

According to our investigation on centenarians, around $64 \%$ of the centenarians sleep more than $9 \mathrm{~h}$, and about $70 \%$ have good or very good quality sleep (Fig. $3 \mathrm{c}$ and $3 \mathrm{~d}$ ), indicating that the centenarians have good sleeping quality in general. Fig. $3 \mathrm{e}$ shows the medical consultation times. $75 \%$ of the centenarians go to clinic less than once a month, but $10 \%$ go more than 3 times a month. The average medical consultation time for centenarians in Hainan is 0.9 per month, slightly higher than average national hospital-visit rate of 5 times per year (Chen, 2013), which is in line with the former research indicating that with increasing age individuals tend to use health services more frequently (O'Reilly, 2004, Chapter 1801). Fig. $3 \mathrm{f}$ indicates the mental state of centenarians. In general, the longevity group had a relatively positive mental state, characterized by reporting that they had a "let it be" attitude when faced with adversity caused by age, and that they felt happy. A negative mental state was characterized by reporting "always feeling nervous or fear" and by feeling lonely. In interviews, most of the longevity group had a positive mental state, and more than $80 \%$ of the aging group had a "let it be" attitude. In terms of dietary habits, the longevity group ate relatively light, plain food and lots of vegetables. As Fig. $3 \mathrm{~g}$ and $\mathrm{h}$ show, the major staple foods for centenarians are rice and flour, accounting for $90 \%$ of all staple food

Table 2

The correlations between per Capita GDP and three aging proportions.

\begin{tabular}{|c|c|c|c|}
\hline & $65+$ proportion $(2010 / 2000)$ & $80+$ proportion $(2010 / 2000)$ & $100+$ proportion $(2010 / 2000)$ \\
\hline Per Capita GDP(2010/2000) & $0.145^{\mathrm{b}}$ & $0.109^{\mathrm{a}}$ & 0.071 \\
\hline $\mathrm{N}$ & 339 & 339 & 313 \\
\hline
\end{tabular}

a Correlation is significant at the 0.05 level (2-tailed)

b Correlation is significant at the 0.01 level (2-tailed). 


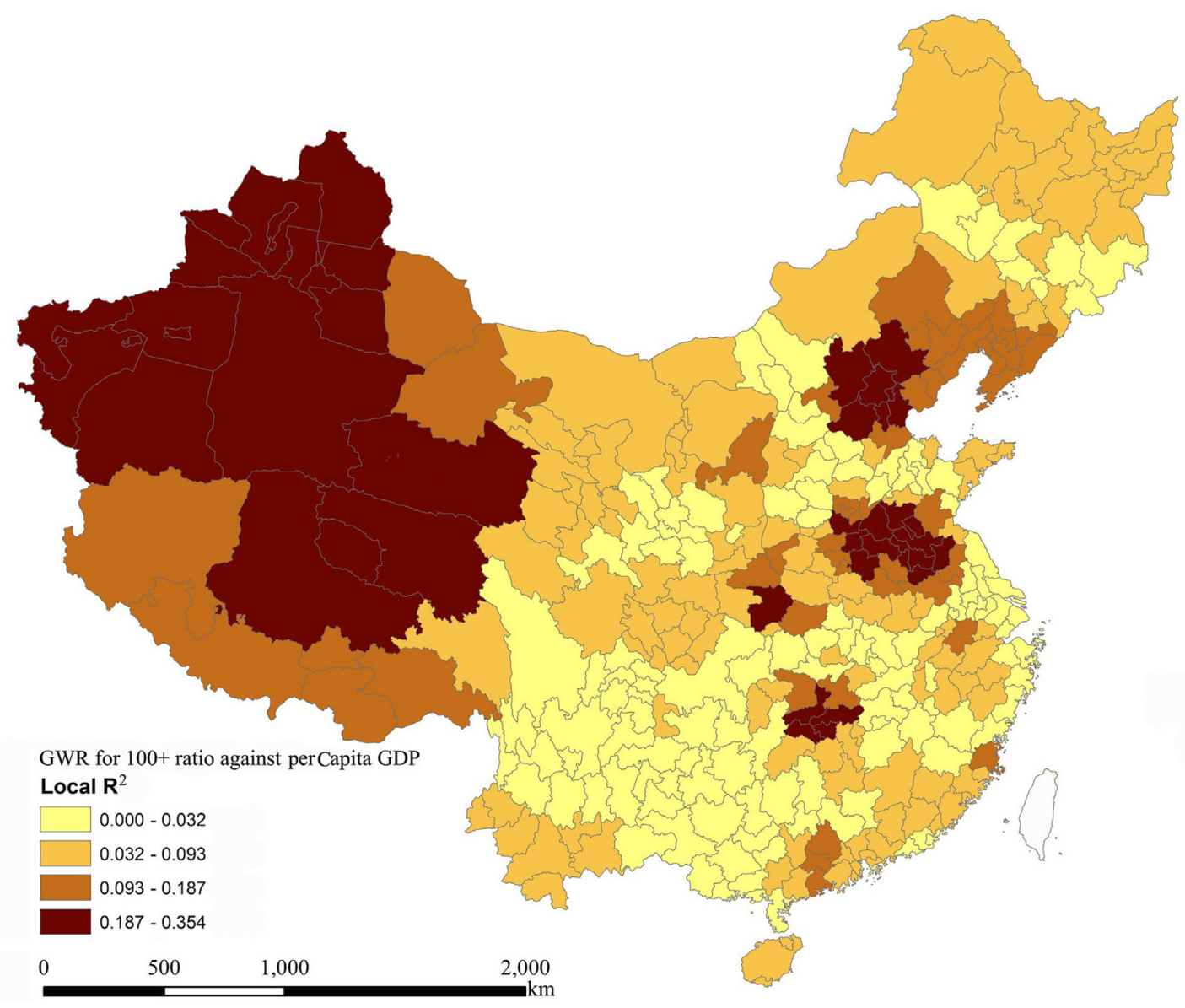

Fig. 2. Spatial correlation of centenarian proportion against per Capita GDP using GWR.

consumption, and around $70 \%$ of them ate light, plain food (food which has a light taste, not salty, not spicy, and not oily) every day. According to our questionnaires, nearly all (90\%) of the centenarians ate vegetables every day, and over than $70 \%$ ate light food every day.

\section{Discussions and conclusions}

Aging is becoming a big public health burden for the whole world, and healthy, active longevity could ease the burden on families and communities. Scientific studies suggest that only about 25 percent of how long we live is dictated by genes. The other 75 percent is determined by our lifestyles and the everyday choices we make (Buettner, 2010). Though controversial and complex, genetic factors (Schachter et al., 1994), climate (Lv et al., 2011a,b; Robine et al., 2012), natural environment (Liu et al., 2013; Magnolfi et al., 2009), socio-economic (Costa, 2005), and individual behaviors (Martin et al., 1996) have already been proven to influence lifespan, and thus influence the spatial distribution of longevity.

The non-random spatial distribution of the longevity group in China was noted two decades ago (Foster \& Zhang, 1995). Our research shows that spatial variation continues to exist at the national and provincial levels. The proportions of the elderly and the oldest old increased largely, but the distribution patterns of those two proportions have not changed too much from 2000 to 2010. Regions with higher ratios of the elderly and the oldest old are mainly located on the southeast side of the "Hu line" which is the climate boundary in China, and regions with high centenarian proportion mainly cluster in South China (Guangxi and Hainan).
Previous research showed moderate climate could affect the lifespan (Robine et al., 2012). Lv [2011] also reported that the "longevity villages" in China were commonly characterized by average temperatures between $8.6^{\circ} \mathrm{C}$ and $24.9^{\circ} \mathrm{C}$, relatively high humidity (68\%), and more sunshine (more than $821.5 \mathrm{~h}$ of sunshine duration) (Lv et al., 2011a; Lv, Wang, \& Li, 2011b). Favorable climate provides abundant natural resources and suitable environment, which is beneficial for living healthier and longer. Former studies revealed that rich Selenium and Zinc in both natural environment and centenarians' body were largely found in China's "longevity villages", indicating those trace elements could influence the geographical aggregation distribution of the longevity, particularly for the centenarian proportion (Liu et al., 2013; Magnolfi et al., 2009; Savarino et al., 2000). Economic factors are also associated with longevity, through adequate food, balanced nutrition, good education, social security, and good access to healthcare, in addition to general satisfaction and happiness (Brown et al., 2012; Yi, D. Gu, \& Land, 2007). In our study, the elderly proportion and the oldest old proportion are positively correlated with per Capita GDP, but no significant correlation was found in general between the centenarian proportion and per Capita GDP. Through GWR, positive spatial correlations between centenarian proportion and per Capita GDP were found in regions like Beijing-Tianjin-Hebei, Henan province, and partly Hunan province. The regions with higher spatial correlations (local R-square lager than 0.18 ) between centenarian proportion and per Capita GDP are not always the ones with higher centenarian proportions, indicating that, though economic could influence living long lifespan, but the influence is very limit when people is getting more and more older. On the other hand, the negative impacts of economic growth, like climate 

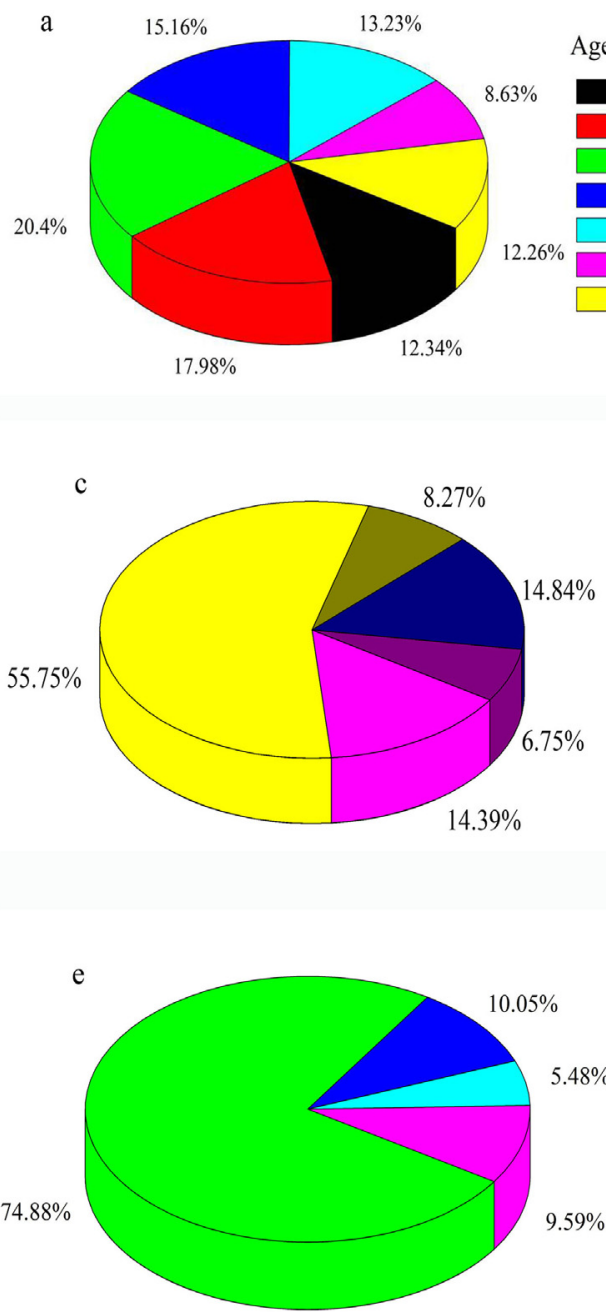

g

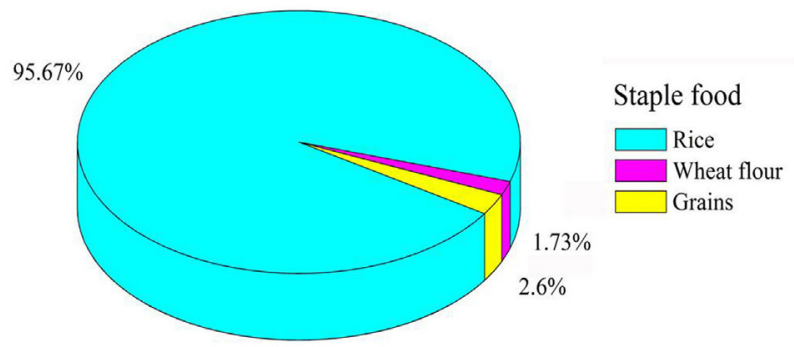
Per month

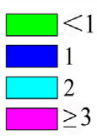

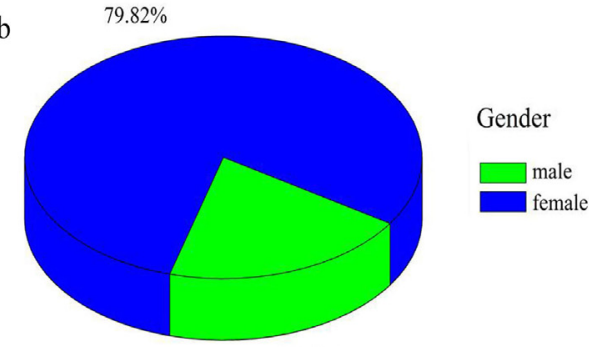

$20.18 \%$
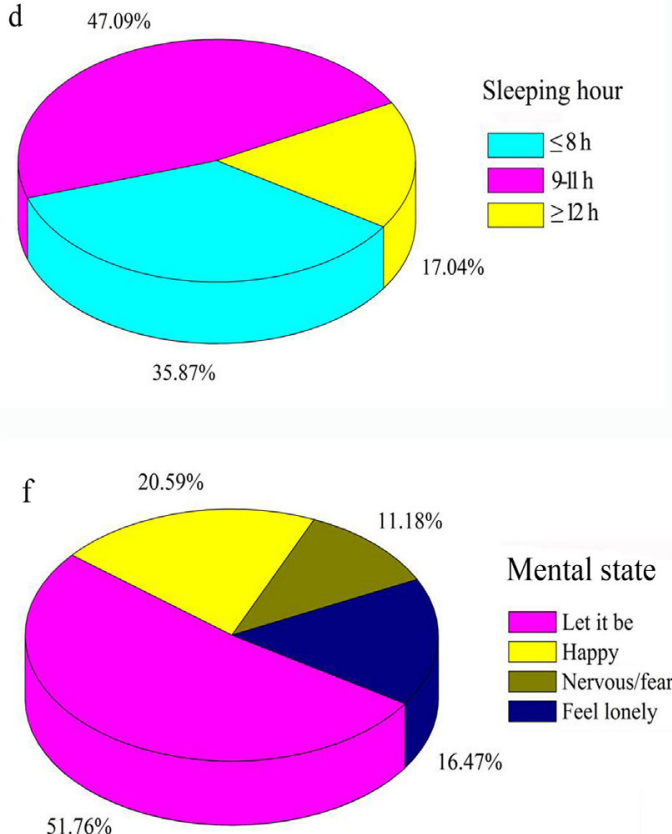

Medical consultation

$51.76 \%$

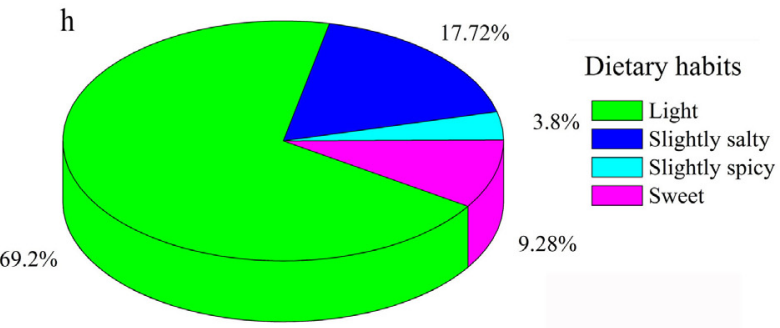

Fig. 3. Centenarian structure and behavior characteristics.

change and environmental pollution might offset some of the benefits brought by the economic development (Wang et al., 2014). The GWR analysis contributes to advancing the knowledge on the spatial distribution of longevity in China. Restricted by the data availability, we only included per Capita GDP as an independent variable. The distribution of longevity is shaped by multiple factors. A multivariate approach synthetically considering environmental, economic and social factors could provide a further understanding on the spatial distribution characteristics of longevity, particularly for China, where the environment pollution is influencing public health at a large scale.

The interaction between behavioral and biological factors, including individual lifestyle choices, physiology, and psychology, plays a crucial role in healthy living (Brown et al., 2012). The famous Okinawan centenarian, Kamada Nakazato, reported that the keys to her long life were to "eat your vegetables, have a positive attitude, be kind to people, and smile"(Buettner, 2010). Quality and duration of sleep have been shown to affect health and reduce mortality (Dew et al., 2003; Kripke, Simons, Garfinkel, \& Hammond, 1979) and an optimistic mental state has also been found to be positively related to longevity probably because it assists in relaxation which can reduce multiple mortality factors (Brummett, Helms, Dahlstrom, \& Siegler, 2006; Diener \& Chan, 2011; Giltay, Geleijnse, Zitman, Hoekstra, \& Schouten, 2004). Laughter, is also positively associated with health, through possibly decreasing the risk of heart attack, lowering blood pressure (Hasan 
\& Hasan, 2009; University of Maryland Medical Center, 2005), or minimizing the negative effects of stress by reducing the breakdown of nitric oxide (leading to vasodilatation) and increasing the number of natural disease-fighting killer cells. Although our research is not aimed to find the causality between mental state and longer lifespan, three-quarters of the centenarians with positive attitude support this theory. Dietary habits are also critical for longer and healthier lifespan. Vegetables are high in nutrients and low in calories, and light food can maintain blood pressure equilibrium and also avoid a wide variety of cancers (Tomonari et al., 2011). Vegetarian diets have been found to be significantly associated with reduced cardiovascular mortality, non-cardiovascular non-cancer mortality, renal mortality, and endocrine mortality (Orlich et al., 2013). In our research, 90\% of the centenarians eating vegetables every day, and around $70 \%$ of their daily diets consisting of light food evidence the fact that high nutrient could help to live longer.

In summary, natural geographic environment and socioeconomic development largely shaped the distribution and variation of the aging, but the influence of economic is less when people getting older. While at micro level, specific features among the centenarians indicate that those life styles or behaviors could be also beneficial for living longer.

\section{Acknowledgement}

This research was supported by the National Natural Science Foundation of China (No. 41171082). Y.-H. L., J.H. and W.-Y. W. designed the study; Z.H. and H.-R.L collected the data; L.W and Y.-H.L. generated the maps and did the correlation; and L.W. and T.K analyzed the data and wrote the manuscript. All authors reviewed the manuscript. The authors declare no competing financial interests.

\section{References}

Banister, J., Bloom, D. E., \& Rosenberg, L. (2010). Population aging and economic growth in China. program on the global demography of aging: Working paper series. Available online. .. [Accessed on 14.09.09] http://www.hsph.harvard.edu/ program-on-the-global-demography-of-aging/WorkingPapers/2010/ PGDA_WP_53. pdf.

Brown, B. Qiu, L. \& Gu, D. (2012). Associations between human rights environment and healthy longevity: The case of older persons in China. Health and Human Rights, 14, 87-105.

Brummett, B. H., Helms, M. J., Dahlstrom, W. G., \& Siegler, I. C. (2006). Prediction of all-cause mortality by the Minnesota Multiphasic Personality Inventory Optimism-Pessimism Scale scores: Study of a college sample during a 40-year follow-up period. Mayo Clinic Proceedings, 81, 1541-1544. http://dx.doi.org/ 10.4065/81.12.1541.

Buettner, D. (2010). The Blue Zone lessons for living longer from the people who've lived the longest. The study guide (Dulexe Edi). National Geographic.

Chen, Z. (2013). The average hospitalization times for Chinese people are 5 times per year. . [Accessed on 15.04.03] http://news.china.com/focus/2013lh/news/ 11136226/20130311/17721221.html/.

China NBS (2011). National bureau of statistics of China. The sixth national population census of the People's Republic of China.

China statistical yearbook (2000). China statistical yearbook. Beijing: China Statistic Press.

China statistical yearbook (2010). China statistical yearbook. Beijing: China Statistic Press.

Costa, D. L. (2005). Causes of improving health and longevity at older ages a review of the explanations. Genus, 51, 21-38.

Dew, M. A., Hoch, C., Buysse, D. J., Monk, T. H., Begley, A. E., Houck, P. R., et al. (2003). Healthy older adults' sleep predicts all-cause mortality at 4-19 years of followup. Psychosomatic Medicine, 65, 63-73.

Diener, E., \& Chan, M. Y. (2011). Happy people live longer: Subjective well-being contributes to health and longevity. Applied Psychology: Health and Well-being, 3 , 1-43. http://dx.doi.org/10.1111/j.1758-0854.2010.01045.x.

Foster, H. D., \& Zhang, L. (1995). Longevity and selenium deficiency: Evidence from the People's Republic of China. Science of the Total Environment, 170, 133-139.
Giltay, E. J., Geleijnse, J. M., Zitman, F. G., Hoekstra, T., \& Schouten, E. G. (2004). Dispositional optimism and all-cause and cardiovascular mortality in a prospective cohort of elderly dutch men and women. Archives of General Psychiatry, 61, 1126-1135. http://dx.doi.org/10.1001/archpsyc.61.11.1126.

Hasan, H., \& Hasan, T. F. (2009). Laugh yourself into a healthier person: A cross cultural analysis of the effects of varying levels of laughter on health. International Journal of Medical Sciences, 6, 200-211.

Hu, Y.-H. (1935). Heihe-Tengchong line, available online. . [ [Accessed 14.12.09] http:// en.wikipedia.org/wiki/Heihe\%E2\%80\%93Tengchong_Line/.

Kinsella, K., \& Phillips, D. (2005). Global aging: The challenge of success. Population Bulletin60.

Kripke, D. F., Simons, R. N., Garfinkel, L., \& Hammond, E. C. (1979). Short and long sleep and sleeping pills. Is increased mortality associated? Archives of General Psychiatry, 36, 103-116.

Liu, Y., Li, Y., Jiang, Y., Li, H., Wang, W., \& Yang, L. (2013). Effects of soil trace elements on longevity population in China. Biol Biological Trace Element Research, 153, 119-126. http://dx.doi.org/10.1007/s12011-013-9673-0.

Lv, J., Wang, W., Krafft, T., Li, Y., Zhang, F., \& Yuan, F. (2011a). Effects of several environmental factors on longevity and health of the human population of Zhongxiang, Hubei, China. Biological Trace Element Research, 143, 702-716. http://dx.doi.org/10.1007/s12011-010-8914-8.

Lv, J., Wang, W., \& Li, Y. (2011b). Effects of environmental factors on the longevous people in China. Archives of Gerontology and Geriatrics, 53, 200-205. http://dx. doi.org/10.1016/j.archger.2010.10.012.

Magnolfi, S., Noferi, I., Petruzzi, E., Pinzani, P., Malentacchi, F., Pazzagli, M., et al. (2009). Centenarians in Tuscany: The role of the environmental factors. Archives of Gerontology and Geriatrics, 48, 263-266. http://dx.doi.org/10.1016/j. archger.2008.02.002.

Martin, P., Poon, L. W., Kim, E., \& Johnson, M. A. (1996). Social and psychological resources in the oldest old. Experimental Aging Research, 22, 121-139. http://dx. doi.org/10.1080/03610739608254002.

O'Reilly, J. T. (2004). The lawyer's guide to elder injury and accident compensation health services for the elderly, 2nd ed. American Bar Association.

Orlich, M. J., Singh, P., Sabate, J., Jaceldo-Siegl, K., Fan, J., Knutsen, S., et al. (2013). Vegetarian dietary patterns and mortality in adventist health study 2. JAMA Internal Medicin, 173, 1230-1238. http://dx.doi.org/10.1001/ jamainternmed.2013.6473.

Robine, J. M., Herrmann, F. R., Arai, Y., Willcox, D. C., Gondo, Y., Hirose, N., et al. (2012). Exploring the impact of climate on human longevity. Experimental Gerontology, 47, 660-671. http://dx.doi.org/10.1016/j.exger.2012.05.009.

Savarino, L., Granchi, D., Ciapetti, G., Cenni, E., Ravaglia, G., Forti, P., et al. (2000). Serum concentrations of zinc and selenium in elderly people results in healthy nonagenarianscentenarians. Experimental Gerontology, 36, 327-339.

Schachter, F., Faure-Delanef, L., Guenot Rouger, H., Froguel, P., Lesueur-Ginot, L., et al. (1994). Genetic associations with human longevity at the APOE and ACE loci. Nature Genetics, 6, 29-32.

Tomonari, T., Fukuda, M., Miura, T., Mizuno, M., Wakamatsu, T. Y., Ichikawa, T., et al. (2011). Is salt intake an independent risk factor of stroke mortality? Demographic analysis by regions in Japan. Journal of the American Society of Hypertension, 5, 456-462. http://dx.doi.org/10.1016/j.jash.2011.07.004.

United Nations (2013). World population aging. New York. . . Available online [Accessed 14.09.09] http://www.un.org/en/development/desa/population/ publications/pdf/ageing/WorldPopulationAgeing2013.pdf/.

University of Maryland Medical Center (2005). School of medicine study shows laughter helps blood vessels function better. . . [accessed 14.09.21] http://umm. edu/news-and-events/news-releases/2005/school-of-medicine-study-showslaughter-helps-blood-vessels-function-better/.

WHO (World Health Organization) (2011). Global health and aging. . . [Accessed on 14.09.09] Available online: http://www.who.int/ageing/publications/ global_health.pdf.

Wang, L., Wei, B., Li, Y., Li, H., Zhang, F., Rosenberg, M., et al. (2014). A study of air pollutants influencing life expectancy and longevity from spatial perspective in China. Science of the Total Environment, 487, 57-64. http://dx.doi.org/10.1016/j. scitotenv.2014.03.142.

Ware, J. E., Snow, K. K., Kosinski, M., \& Gandek, B. (1993). SF-36 health survey: Manual and interpretation guide. the health institute, new england medical center. available online. . . [Accessed on 14.09.09] http://czresearch.com/info/ SF36_healthsurvey_ch6. pdf.

Yang, G., Wang, Y., Zeng, Y., Gao, G. F., Liang, X., Zhou, M., et al. (2013). Rapid health transition in China, 1990-2010: findings from the global burden of disease study 2010. The Lancet, 381, 1987-2015. http://dx.doi.org/10.1016/s0140-6736(13) 61097-1.

Yi, Z., Gu, D., \& Land, K. C. (2007). The association of childhood socioeconomic conditions with healthy longevity at the oldest-old ages in China. Demography, $44,497-518$.

Zhang, L., \& Wilson, D. P. (2012). Trends in notifiable infectious diseases in China: Implications for surveillance and population health policy. PLoS One, 7, e31076. http://dx.doi.org/10.1371/journal.pone.0031076. 